\title{
Performance assessment in education for sustainable development: A case study of the Qatar education system
}

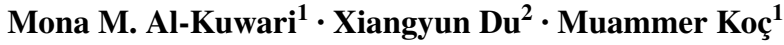

Accepted: 18 August 2021 / Published online: 24 September 2021

(C) The Author(s) 2021

\begin{abstract}
Various studies show that sustainability and education are closely interdependent. Design and implementation of the right performance assessment for students' skills acquisition and achievements is, therefore, critical for achieving the Sustainable Development Goals (SDGs). This article presents an in-depth analysis of the Qatar education system (K-12 level), focusing on the current assessment approaches and remaining challenges that hinder the development and implementation of proper performance-assessment methods aligned with SDGs. Based on a proposed theoretical framework influenced by the constructive alignment theory, this article examines the current performance assessment practices in Qatar and recommends potential improvement avenues with respect to SDGs and education goals (EGs). Using this framework as an analytical tool, results reveal a lack of alignment between the assessment practices, educational goals, and the SDGs. This work shows that tailored, contextually proper, and progressive assessment strategies need to be developed to accurately evaluate and guide the twenty-first-century skills of the students toward the achievement of SDGs. Further findings of this article concern presentation and discussion of the locally relevant and consistent recommendations for performance assessment methodologies that must be redesigned to be compatible, aligned, and supporting the SDGs and EGs.
\end{abstract}

Keywords Sustainable development - Constructive alignment - Performance assessment . Qatar education system

Mona M. Al-Kuwari

monalkuwari@hbku.edu.qa

$\triangle$ Muammer Koç

mkoc@hbku.edu.qa

Xiangyun Du

xiangyun@qu.edu.qa

1 Division of Sustainable Development, Hamad Bin Khalifa University, Qatar Foundation, Education City, Doha, Qatar

2 College of Education, Qatar University, Doha, Qatar 
In 2015, many countries came together to conclude the United Nations' extensive efforts in launching its 17 Sustainable Development Goals (SDGs). Among these goals, the fourth goal (SDG 4) puts a great emphasis on quality education and the promotion of quality learning for all (UNESCO 2017). This emphasis reflects the effective role of education, which can be a means of enabling many aspects under SDGs such as economic growth, health, inequality reduction, and poverty elimination.

Education for sustainable development (ESD) aims to develop integrated thinking, enhance living, improve decision-making, and ameliorate action patterns for interdependent environmental, cultural, social, and economic systems in order to promote sustainable living for both current and future generations. Given the interdependency of environmental, cultural, social, and economic systems, education plays a central role, since its impact is at the heart of these systems (Nevin 2008; UNESCO 2012). ESD can address the SDGs by (1) embedding them into the curriculum, (2) having all education institutions and stakeholders share the principles and values that support sustainable living and actions, (3) promoting problem solving, critical thinking, and action that can accurately address the sustainability challenges, (4) applying diversity in education methods, (5) involving learners in decision making, and (6) raising awareness in addressing local and global challenges (Nevin 2008).

Ideally, the education system of countries that have high standards of learning and are relatively well-aligned toward SDGs should ensure the education and preparation of future citizens, giving them knowledge, understanding, and habits-twenty-first-century skills that make them ready to be part of the workforce and civil society, and to meet the complex challenges of modern times such as sustainability and resiliency. These skills will, then, ensure the efficiency and effectiveness of future workforces in the society.

Qatar has adopted sustainable development (SD) into its national development vision (GSDP 2018a), strategies (GSDP 2018b; 2011), and ministerial and sectoral plans as well as its education strategy (MOEHE 2018b). Its education system-the Qatar Education System (QES), especially on the K-12 level-has also been making efforts to integrate ESD into learning and teaching in order to provide the knowledge, attitudes, and skills that are necessary to achieve the SDGs.

Still, though, with the exception of few countries and despite the efforts made by these education systems to ensure that students acquire the essential knowledge, skills, and capacity to achieve a whole understanding and habits for sustainable living and SDGs (Nordensvaard 2014), many countries fail to use proper methods of assessing students' understanding. Currently, these efforts are missing a reliable, adaptive, and holistic framework of performance assessment (PA), which would measure the achievement level in regard to desired goals of education and sustainability as well. To focus more specifically on the example of Qatar, the QES continues using conventional PA, which hampers, if not prevent, rapid and effective realization of SDGs and its specific EGs. This is true even though it is proven that initiatives in integrating SDGs within the QES need to be supported by constructive, tailored, and progressive PA methods that focus on a multitude of skills development instead of information acquisition. We examine, as a case study, the current situation and proposes a framework for PA constructively aligned with SDGs within the QES.

This research attempts to understand and analyze issues and challenges related to existing PA strategy for the QES. It focuses on the PA aspect as a sub- and interactive-system element of the entire education system. We anticipate that such a reconsideration-and consequent improvements - can offer opportunities to equip a new generation of students and graduates with analytical and critical thinking skills, innovative and creative 
approaches to problems, high morals and purposefulness to meet the needs of knowledgebased, sustainable development. In this study we will explore the ways in which current PA practices contribute to the SDGs, in particular. In a second step, we aim to establish a conceptual framework on PA for ESD in the QES. Based on a comprehensive and critical analysis of the literature, we lay out the state-of-the-art practices and strategies related to PA.

To perform this analysis, we searched for relevant articles and reports from databases such as ScienceDirect and ResearchGate using selected keywords, which included "SDGs", "ESD", "K-12", "PA", "QES" in different combinations, in addition to compiling some papers that an expert in the field of education and PA recommended. Most of the selections are peer-reviewed scientific papers or from journals with a high impact factor index. The search resulted in around 180+ documents. For the second step we analyzed the content of selected documents by reviewing their title, authors, and abstracts, a process that reduced the number of relevant articles to around 100. Of these, we found only approximately 75 addressed common theories of PA and the various practices that existed up until the time of this search; that is, between November 2019 and January 2020.

We divided the article into four sections. Following the theoretical framework in the first section, section 2 covers the findings from literature studies in terms of PA theories, and establishes the framework of PA that is constructively aligned with SDGs. Section 3 provides a theoretical analysis of the QES with respect to current PA practices. The fourth section discusses the results and the analysis of the QES, and offers recommendations for redesigning a new PA framework. The last section presents conclusions and future work in this arena.

\section{Theoretical framework}

\section{Constructive alignment in education}

Education is considered as a complex social system due to its large number of stakeholders and interdependent relationships between its elements. Thus, it is not an easy and straightforward process to identify problems and come up with proper solutions in such a complex system with its intertwined elements, processes, and interlinkages. To solve various educational issues, many researchers, such as Yunianta et al. (2015), aim to analyze the aspects of heterogeneity in the learning environment by using constructive alignment (CA) theory, which is an educational model to direct a better learning process. The concept of this theory is that the actions of learners specify what is learned and that knowledge is constructed through students themselves (Brabrand 2008).

John Biggs (2003) defined the idea behind CA, that students construct their learning through relevant learning activities. Also, he pointed out that the essential role of teachers is to build a proper environment for learning, one that can provide suitable support for learning activities so that students can achieve the intended learning outcomes. From here, the concept of "alignment" refers to the effective role of the teacher and what he/she does. The teaching system components include assessment tasks, teaching methods, and the intended learning outcomes; the key is that all of these components are aligned with each other. Therefore, this concept can be a guarantee that students learn appropriately (Biggs 2003). First of all, by setting up an aligned system, one can identify the desired teaching outcomes in the contexts of subject content and of students' level of understanding. 
Second, the learning environment can be set up to raise the chances of engaging students in activities designed to achieve the desired outcomes. Last, the proper assessment tasks can detect how well individual students have acquired these outcomes. In summary, the following are the main steps:

- $\quad$ specifying the intended learning outcomes (ILO)

- selecting the teaching and learning activities (TLA)

- assessing students' learning outcomes (PA)

- awarding the final grade (PA)

Ortega-Sanchez (2016) wrote that, when designing a course, the first step is to decide what knowledge and skills the students should learn in that course. In order to achieve the intended goals overall and SDGs, in specific, one should distinguish between two types of knowledge. Declarative knowledge refers to basic facts, memorized information, and functioning knowledge-in which the students learn how to transform declarative knowledge into functioning knowledge (Biggs 2003). Functioning knowledge would be the best method to achieve the ILO of SDGs, as it is the knowledge that one puts to work in solving a problem or analyzing a case study that may relate to sustainability issues. Moreover, instead of the traditionally limited resources for teaching, learning outside the class, with interactive teamwork, self-directed learning, peer teaching, and work-based learning, can be a rich source of learning activities toward achieving the SDGs. Some of the studies proposed using CA, which can assist in designing, integrating, and evaluating programs that are coherent with sustainability competencies for ESD and SDGs. This result confirms the findings of Wilhelm et al. (2019), who described ESD competencies-which include knowledge, values, skills, and attitudes-by offering a model that uses CA in terms of ESD competencies and focuses more on the individual's ability to take action to shape the future.

Over the decades, while the concept of CA has been well used at the micro-level of classroom teaching design in order to support student-centered learning, it is less discussed at a macro level of educational system. This research is an attempt to give this concept a broader scope, of critically analyzing the educational system with the goal of sustainable development. In practice, the concept of CA will inspire the establishment of a framework that will be used to critically analyze the current educational assessment system in Qatar.

\section{Theories of performance assessment}

Educators and others have developed and used a variety of student's assessment methods in various institutes for different purposes, and that have even greater variations in their implementation. When it comes to implementation, though, these methods are missing a systematic approach and, hence, do not provide an opportunity for cross-comparison and peer learning (Rust 2002). According to a theory developed by Rust (2002), impacts of PA should not be limited to assessment outcomes and strategies but should go beyond them to cover course design and learning approaches overall. In the following section, we present a more critical analysis of some of these assessment methods and approaches.

The Aalborg model, also known as Aalborg PBL (project and problem-based learning), is an educational philosophy and methodology followed not only in facilitating studentcentered learning but, more importantly, in supporting education systems to develop and align SDGs. The PBL approach, characterized by using problems, projects, and teamwork as the basis of teaching and learning, has been well documented as a useful way of 
implementing sustainability goals. However, PBL can be based on multidisciplinary subjects that are structured more by teachers. Meanwhile, the concept of PBL is an educational approach, where the selected problems are considered as a starting point and usually are related to real-life problems, as well as aligned with educational objectives and criteria (Holgaard et al. 2016). Experience learning is also a principle of this learning approach, where the student formulates the problem statement based on his or her interests and experiences, which enhances their motivation and comprehension. The formulation of the problems by students is a Danish concept called participant-directed, or self-directed, learning.

Recently, the PBL approach has been increasingly implemented in the Qatari educational context, with evidence that it may be a useful pedagogical approach in K-12 settings to improve twenty-first-century skills (Du et al. 2019). Nevertheless, while recent studies identified the benefits of PBL in supporting reaching Qatar educational visions (e.g., twenty-first-century skills), gaps were revealed between the prevailing assessment methods across all educational levels that focus on basic knowledge and information retention instead of professional-related skills and competences, and the educational goals the country aims to achieve (Du et al. 2019). Although PBL is perceived as one of the best methods to facilitate and measure twenty-first-century skills and to evaluate knowledge beyond the mere learning of higher-order skills and competencies, it is a complex and difficult matter to borrow educational methodologies evidenced as effective in a Western context and implement them in a Middle Eastern context. This is QES and school leaders regard teachers and textbooks as the major and sole authorized source of knowledge, rendering the application of PBL in the Qatari K-12 system more of a challenge. (Du et al. 2019). According to Said (2016), PBL is still considered a new pedagogical phenomenon in Qatar public schools. It needs qualified teachers to implement and perform since it relies on teachers' capabilities and their professional development program.

Other models of assessment, which recently are widely used, are the summative and formative approaches. The purpose of the summative is to evaluate student performance overall-mostly at the end of the term or the semester and usually relying on memorized and retained information; whereas, formative assessment is about increasing performance quality through continuous monitoring of students' work and giving regular feedback in order to improve students' weak areas (Dixson and Worrell 2016).

Comparing formative and summative assessments: the latter uses very limited tools and format to assess whether students have acquired cognitive skills (Finnegan et al. 2019). Further, students suffering from learning difficulties may not understand the questions posed in summative assessments. In addition, such assessments do not offer accurate information, since they can lead to more risk of measuring wrong aspects by relying on testing students memorization capability rather than the actual purpose of learning (Fisher 2019). The summative assessments did not support the comparisons over the schools' performance among different classes and grades and did not assist teachers in monitoring the progress of students (Brewer 2007). On the other hand, as discussed before, the capability of various teachers in Qatar government schools is considered as barriers to implementing a new concept of pedagogy approaches or assessment practices such as formative assessment in classrooms. This is mostly due to lack of teachers' knowledge about this type of assessment and the lack of professional trainings in this area. Additionally, the relatively large classroom sizes and the time it takes for this kind of class activities are other reasons why teachers don't use formative assessment effectively. Using these assessments can also add heavy workload on teachers. Moreover, their extent to accepting changes can impact the effectiveness of implementing formative assessments (Quyen and Khairani 2017). However, assessment extends beyond examining which stakeholders can benefit from this 
measurement - it also looks at, for example, teaching practices and parental satisfaction. Efficient measurement tools, such as formative assessment, can provide the data for continuous improvement of pedagogy throughout the whole system (Gonzalez et al. 2009).

\section{Developing a framework of PA constructively aligned with SDGs}

In recent decades, the debate on test-driven accountability practices has increased remarkably. Therefore, it is important to emphasize that educational reforms should include the improvement of educational practice and the reconsideration of the standards of performance to assure that all students are qualified for life, college entrance, and workforce readiness in a competitive and innovation-driven economy. A framework for performance assessment aligned with EGs and SDGs (PA-SDG/EG) aims to use CA theory in order to align all elements of education with each other for an improved learning process in the context of SDGs, Fig. 1 shows the mapping of the process, which is considered a macro model in comparison to the Biggs model.

Bloom's taxonomy (1956), as a hierarchal ordering of cognitive skills, can help educators to set up and classify the educational learning objectives related to the SDGs (Pappas et al. 2012). Sustainability competencies are indispensable for building

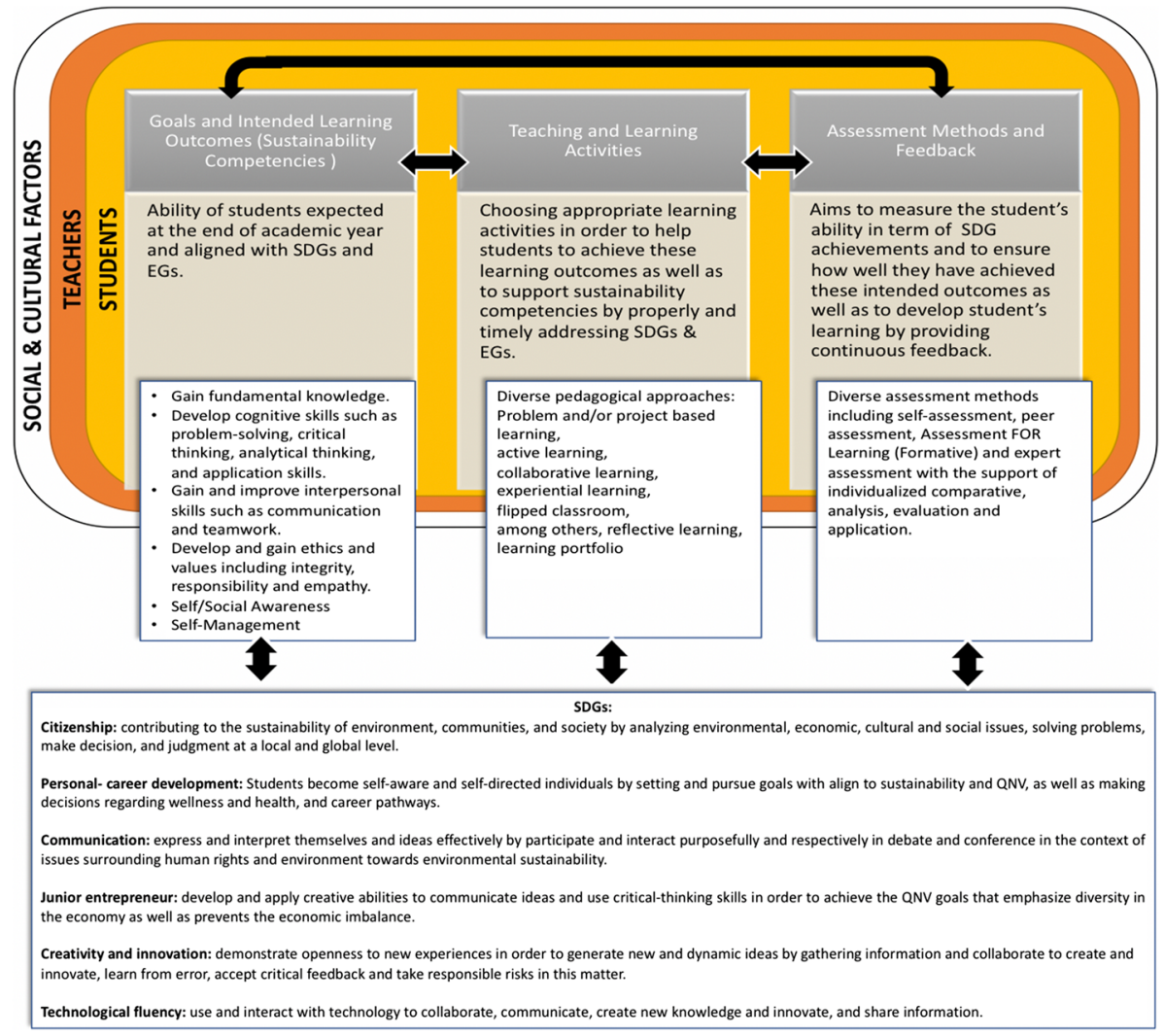

Figure 1 The framework of performance assessment aligned with SDGs (PA-SDG/EG).

Source: Biggs and Tang (2011). 
capacities, which enable students to think critically about unsustainable patterns of behavior, which empowers them to make proper decisions and act for change (Dlouhá et al. 2019). Sustainability competencies are essential to enabling students to review current policies and values critically in order to redirect the practices of human activities towards sustainability (Fischer \& Barth 2014).

Regarding the proposed framework, the listed competencies in the SDGs and the intended learning outcomes are prerequisites for sustainable literacy, awareness, and actions. First, these competencies are necessary for applying available knowledge and for using analysis as well as evaluation to address sustainability issues such as: climate change, energy inefficiency, water scarcity, air pollution, food security and issues related to national security (UNESCO 2017). These are prerequisites to enable students to make decisions and to act in complex situations of sustainability by assisting learners in applying the available expertise in the context of sustainability practices as well as guide their individual choices to become active citizens and proactively (Dlouhá at al. 2019; Pierre et al. 2014; Zhou 2016).

In the proposed framework of PA-SDG/EG, the learning activities were listed to ensure that the intended goals will be achieved in the context of the SDGs and EGs. This was emphasized by Albareda-Tiana et al. (2018) when they proposed that preparing for future sustainability challenges and effective participation, as core factors of ESD, requires changes in pedagogical approaches to competency-based teaching and learning. Similarly, Biasutti et al. (2018) revealed the need to restructure education by canceling the twentieth-century assembly-line approach and replace it with twenty-firstcentury models of teaching that rely on interactivity, critical analysis, and collaboration in the ESD context.

One of these pedagogical approaches is problem-based learning (PBL), also called the Aalborg model (see above), which can rapidly develop to support sustainability competences (Barth and Rieckmann 2016). Another approach that enhances students' innovation is creative problem-solving, which involves searching for a novel solution to a problem related to sustainability issues. Team-based learning (TBL) is another effective teaching method to enhance cognitive and noncognitive skills in students by developing their interpersonal abilities by encouraging their interaction and teamwork. According to Cörvers et al. (2016), when students address real-world sustainability issues by collaborating in small teams in order to solve problems, their learning often shifts from passive to active.

Educators use many methods to assess students, but the critical issue is which one most effectively measures students' ability to apply the knowledge and skills taught in their studies (Darling-Hammond and Adamson 2015). Recently, there is growing interest in classroom formative assessment and its potential for improving student learning (Hill 2017). In order to develop students' critical thinking, problem-solving, and communication skills, some teachers use classroom-based assessments, including applied science experiments, research papers (essays, case analyses, and article critiques), and presentations.

In the recent decade, teachers have used peer and self-assessment to improve students' performance significantly by engaging students in assessment design, negotiation of criteria, and assessment tasks as well as with grading exercises (Price et al. 2001). According to Dengler (2008), peer assessment is an active learning tool that can help to develop written communication skills as well as critical and creative thinking. These methods can enhance students' cognitive skills; for example: evaluation, in which students evaluate ideas based on standards, then they judge information, and, finally, weigh evidence or answers. 
Using this theoretical framework, the research questions of the present study are as follows:

(1) What are the challenges of the current QES from the perspective of the contribution of PA practices to the SDGs and ESD?

(2) What are the potentials and possibilities to improve the QES through developing the future of PA practices to achieve the SDGs?

\section{Analysis of the assessment and learning outcomes of QES}

In this section, we use the proposed framework PA-SDG/EG to understand and interpret the educational practices in Qatar so as to analyze in which ways current assessment practices are in line with the educational goals for sustainable development. This analysis is also a way to provide answers to the research questions regarding challenges, issues, potentials, and opportunities. Concretely, the framework plays a guiding role both in judging the current assessment and learning/teaching approaches at QES from the perspective of their suitability for measuring educational outcomes, and in providing ideas for improvement.

In the past decade, the Qatari government has introduced reforms and initiatives in the QES to establish a strong and effective base for human capital development to support the aspirations of the Qatar National Vision (QNV 2030) (Alkhater 2016; GSDP 2018a). Although there have been significant reform attempts and investments since the early 2000s, the QES output indicators still signal that student and graduate achievement levels are far from providing an acceptable quality of education comparable with leading educational systems internationally (Fadlelmula and Koc 2016). With the beginning of the new millennium, the quality of the QES became the main issue of much public concern. Indeed, this issue was reaffirmed when students were academically dismissed from the national university. From 2004 to 2007, with the increasing number of dismissed students from Qatar University, Qatari leaders started to look into the reasons behind this problem.

This section focuses on various types of assessments in public schools for K-12, including national (Qatar Comprehensive Educational Assessment, or QCEA), and international (such as PISA and TIMSS). For grades 1-11, the teacher is responsible for setting up the exams for his/her class. Regarding grade 12, a group of administrators from the Qatar Ministry of Education and Higher Education (MoEHE) sets up the national exam annually. The result of the exam is an official score for the secondary certificate. Based on this score, the student can be eligible to apply for domestic universities, or to obtain a scholarship from the MoEHE or sponsorship from other Qatari institutions and companies to study abroad or locally.

Committees comprised of the student's teachers, instructors from other schools, and a supervisor for each committee to correct the exams. In order for us to have more clarification regarding this process, we contacted some of the teachers from different government/ public schools (M. Z. 2019). They stated that teachers do not get to grade their students and, thus, do not violate grading policies by possibly inflating those grades. Even when the teachers get the exam sheets, usually the names are hidden and they do not see whose sheet they are grading. The main reason behind this procedure is to make the evaluation more transparent and less biased. As indicated above, committees managed by MoEHE prepare and correct the national exams for grade 12 .

The examination format relies on measuring memorization rather than cognitive skills. It uses a summative assessment method at the end of each term, and represents $95 \%$ of a 
student's total GPA. The published MoEHE reports indicate that public schools use different assessment approaches—such as projects, quizzes, and portfolios-but since only $5 \%$ of these assessments comprise a student's total score, students are not motivated when doing these practices, which require a significant amount of effort and time (MoEHE 2018a).

Recent literature exposes that reliance on the summative assessment method as a core evaluation for students has many disadvantages. One of the main disadvantages is that such method focuses on output at the end of term, which prevents struggling students from correcting their mistakes and developing their understanding, as they do not have a chance to recover (Finnegan et al. 2019). Also, such late-term pressure can badly affect the students' psychology - many become very anxious since so much of their future depends on this one exam-which leads them to poor performance.

Graduates from secondary public schools suffer from the gap between their skills and those required for universities (Baghdady 2016). In the year 2016-2017, the secondary stage (grades 10-12) in public schools had the lowest success rate in the exams compared to other stages and to private schools (MoEHE 2017). The rate remained quite low for this critical stage, which means that the graduates were not well equipped for the tertiary education stage. Although these students passed the national exam for grade 12, not all of them were eligible for admission to universities inside Qatar or to get the scholarship.

The assessment system in Qatar was developed over the years by initiating the first standardized, national, and standards-based assessment, called "QCEA". Approximately 88,000 students participated in QCEA, which assessed their skills in Arabic, English, science, and mathematics. In the academic year 2015-2016, the name QCEA changed to "National Assessments". Even though the exam is limited to grades 3, 6, and 9, there is still a decrease in the students' scores in all subjects. In a study published by the RAND Corporation, the system was intended to provide comparisons of students' performance between schools for improvement purposes (Brewer 2007), supplying teachers with appropriate feedback as well as facilitating parents' in choosing schools. In contrast, the RAND Corporation, based on its own assumptions, determined the aims of national standardized assessment, and thus the implementation process missed dealing with a dynamic reality. The consequence is that teachers do not use the results to the utmost potential as feedback to improve student achievement, nor do parents use this test's results.

Qatar has participated in international assessments: PISA in 2006 and TIMSS in 2007. It is clear from the MoEHE reports that there have been slight improvements over the years in the TIMSS results in mathematics and science for the fourth and eighth grades; however, Qatar still ranks lower than the world averages (500 scores). In 2015, the math test showed that only 3\% of Qatari fourth graders reached the highest scores, and 35\% of them failed to achieve the minimum target level. Of 57 countries participating in the PISA test, Qatar classified as the second-to-last, which means the student scores were falling at level 1 (the lowest level of proficiency).

With reference to the MoEHE reports, the QES indicators have reached a reasonably acceptable level in quantity (such as ratios of students to teachers, schools, and expenditures). However, they are still low in quality in terms of academic performance in science and mathematics, and even in reading and comprehension of the native language, in both international and national assessments (Fadlelmula and Koc 2016).

Indeed, even though recent educational literature have highly debated and criticized the international assessments concerning their suitability and fitness to accurately and rightly assess human development with respect to EGs and SDGs (Ramirez et al. 2018), these assessments are still used as essential indicators of the effectiveness of the reforms and 
progress of educational systems such as QES. Another issue, highlighted in various studies, is that these international assessments do not emphasize and fully promote twenty-firstcentury skills such as critical thinking or problem-solving.

Recent studies have exposed the low motivation of Qatari students in primary education, and particularly among male students, the majority of whom just want to pass the academic year but make no progress in their academic achievement (Abou-El-Kheir 2017). This demotivation is mainly due to learning activities that lack variety and do not support student interests. Another challenge that faces the QES is that approximately 95\% of nonQatari teachers have varying qualities, backgrounds, and professional and social aspirations (MoEHE 2017). The quality of teachers directly affects the overall quality of student achievement in academic, social, and moral dimensions, education goals, and the education system overall. Therefore, any changes in the development of teachers, starting with their own education, training, recruitment, retention, promotion, etc., will have direct impacts on the education system.

In the proposed framework, the layer of "teachers" includes elements such as performance assessment, teaching activities, learning outcomes, and students. Students' interactions with teachers and the other teaching-related elements are direct and continuous; it is the teachers' responsibility to achieve the intended learning outcomes through pedagogy as well as assessment. Biggs and Tang (2011) point out that it is essential for teachers to have knowledge of pedagogical approaches and the CA concept in order to teach effectively and achieve good learning outcomes. Albareda-Tiana et al. (2018) and Biasutti et al. (2018) indicate that critical/creative thinking and preparing for future sustainability challenges require a change in teaching/learning activities and need substantive knowledge in this area in order to connect the development of behavior, skills, and values with all relevant educational strategies as well as SDGs.

In QES, the linkages between these elements are not well thought out and acted upon properly. Thus, QES still faces challenges in achieving the intended learning outcomes and improving the students' performance in the assessments. Therefore, most of the recent research and most academics support the use of a curriculum-mapping approach to facilitate alignment between intended learning outcomes, teaching activities, and assessment methods (Biggs and Tang 2011). This also will facilitate the linkage of SDGs and EGs with other factors in the QES and other education systems.

\section{Analysis and discussion}

In this work, we use the theoretical framework called "PA-SDG/EG", first of all, to understand the QES and, secondly, to analyze it in order to identify current assessment practices and learning/teaching activities in terms of their aid in achieving educational goals. Based on this understanding and analysis, we developed recommendations for improvements in assessments and teaching practices geared toward meeting the SDGs. Using the PA-SDG/ EG framework as a guide to evaluate current QES assessment approaches and learning/ teaching activities provided answers to our research questions regarding these elements' suitability for measuring the EGs. We believe that the changes we recommend would enhance the efficiency and effectiveness of the education system and help prepare a new generation of learners with the twenty-first-century skills that our society needs to meet the requirements of knowledge-based sustainable development (GSDP 2018a; MoEHE 2018b). 
Regarding the first research question-which is related to the several challenges and issues of the current QES from the perspective of the contribution of PA practices to the EGs and SDGs-we critically discuss two major challenges. First, there is a lack of theoretical support for the current assessment practices. As a critical component of educational practice and research, theoretical frameworks help practitioners and researchers to organize and create a strong argument to justify the significance of a given problem and guide the selection of appropriate practice and research methods (Antonenko 2015).

Second, analyzing the current assessment practices using the proposed framework reveals a clear gap between the assessment and goals in Qatar. Based on the examples provided in the above section, we see that the assessment methods are mainly focused on testing basic fact-based information and knowledge without addressing profession-related competencies or twenty-first-century skills, as expected by the overall educational goals and the Qatar National Vision. This is shown by the fact that $90 \%$ of assessment methods in Qatar public schools rely on traditional methods that use rote memorization and lack practices that develop the student's abilities such as solving problems and critical and analytic thinking. Beyond literacy and numeracy, our students need the skills required for a knowledge-based society, especially in areas such as research and development, and which would make their future more sustainable. Consequently, as expected, many Qatari students have not as yet realized the desired educational achievements and outcomes. This also explains the low performance of students in both national and international assessments. This problem becomes obvious when students are exposed to new examination formats-which pose questions not directly linked to the curriculum and thus are different from assessments that the students are used to. As a result, using foreign types of assessments, without any coordination between them and the ones students are used to, can distract students and demotivate them, as they will consider this as an extra burden on them.

Although the MoEHE recognizes the importance of twenty-first-century skills and SDGs to develop the abilities of students, neither learning activities nor assessment methods are currently supporting these intended outcomes and, further, neither are aligned with the SDGs. Moreover, these educational practices need qualified teachers with sufficient knowledge in pedagogical approaches. Yet, according to the theoretical analysis of the QES that pointed to many major challenges, there is a shortage of teachers with adequate capabilities and professional expertise, as the majority of them come from foreign countries and thus have unrecognized qualified teacher status (QTS).

We posed the second question of the present article with the goal of finding potential improvements for the QES with respect to exam methods, learning/teaching activities, and education outcomes. After exposing the challenges that the QES faces, here are the possibilities and recommendations based on the framework we developed, with its suggestion for each component:

- First, decisions on educational practices and assessments should be based on a theoretical framework used to guide the development of strategies and the evaluation of the practices. This is essential in aligning educational elements with SDGs and EGs. The proposed theoretical framework, PA-SDG/EG, may serve as a useful instrument in Qatar to further enhance the ESD toward achieving the SDGs.

- Second, educational policies should allow teachers more autonomy in designing appropriate and coherent teaching activities and assessment practices, which can be constructively aligned to the overall goals. These contextualized educational designs shall maximize the values of individual learners according to their needs and the nature of the subject. To bring continuous improvement to the educational policies regarding 
assessment practices and pedagogical approaches, policymakers should give further consideration to continuously training teachers at government schools by providing effective professional development programs that can assist them in implementing new practices.

- Third, educational methodologies that have been evidenced as useful to support ESD, such as PBL, should be systematically introduced into Qatari educational practices. To make their implementation even more effective, each pedagogical approach should be examined within a specific learning context, as each learning environment has a different impact on an approach. Testing them and understanding the coordination between all educational elements in the implementation phase can pinpoint issues and gaps and, hence, facilitate a better adaptation of these approaches.

- Fourth, government and educators should support more comprehensive educational research in this field to gain empirical evidence of the effect of PA in terms of the overall ESD toward reaching the SDGs in Qatar.

In conclusion, any education system around the world needs to apply continuous improvement, including as regards learning activities, intended goals, and assessment techniques. These improvements should be part of the learning and teaching culture of our education system. In fact, this is essential, since every new generation has emerging needs that are different from those of previous generations (Kolmos 1999).

\section{Conclusion}

This research focuses on PA from a quality perspective as it is a vital pillar in the education system. We examine how assessment can be designed in alignment with both SDGs and EGs. The research is part of a long-term project that aims, first, to examine the main reasons behind low performances in the assessments of the QES, and second, to study the best practices of assessment techniques to ensure that cognitive skills are measured properly from the perspective of the SDGs. The theoretical framework that we here propose, named PA-SDG/EG, is based on CA theory under the overall goals of SDGs and is inspired by extensive review of academic literature in this field. We used this framework in order, first, to understand QES and, second, to analyze the issue of assessment practices. Based on this proposed framework, we have explored the current issues of the QES, focusing on the PA aspects and their effect on the education system's outcomes, learning quality, and achievements.

As it stands, the QES is missing a proper alignment of its system components with EGs in general and with SDGs in specific. Our theoretical analysis of the assessment techniques in the QES exposes that a proper assessment system still needs to be developed as the current one is inappropriate for evaluating and guiding the teaching of twenty-first-century skills that support the achievement of the SDGs. For this work to be more comprehensive, the next steps are to develop the proposed framework and to validate it by conducting a survey with the main stakeholders in the education field.

Funding Open access funding provided by the Qatar National Library. 
Open Access This article is licensed under a Creative Commons Attribution 4.0 International License, which permits use, sharing, adaptation, distribution and reproduction in any medium or format, as long as you give appropriate credit to the original author(s) and the source, provide a link to the Creative Commons licence, and indicate if changes were made. The images or other third party material in this article are included in the article's Creative Commons licence, unless indicated otherwise in a credit line to the material. If material is not included in the article's Creative Commons licence and your intended use is not permitted by statutory regulation or exceeds the permitted use, you will need to obtain permission directly from the copyright holder. To view a copy of this licence, visit http://creativecommons.org/licenses/by/4.0/.

\section{References}

Abou-El-Kheir, A. (2017). Qatar's K-12 education reform: A review of the policy decisions and a look into the future. OSF Preprints.

Albareda-Tiana, S., Vidal-Raméntol, S., Pujol-Valls, M., \& Fernández-Morilla, M. (2018). Holistic approaches to develop sustainability and research competencies in pre-service teacher training. Sustainability, 10(10), 3698 .

Alkhater, L. R. M. (2016). Qatar's borrowed K-12 education reform in context. In L. R. M. Alkhater, M. E. Tok, \& L. A. Pal (Eds.), Policy-making in a transformative state: The case of Qatar (pp. 97-130). Palgrave Macmillan.

Antonenko, P. D. (2015). The instrumental value of conceptual frameworks in educational technology research. Educational Technology Research and Development, 63, 53-71.

Baghdady, A. (2016). Transforming Qatar's PSE: Achievements and concessions. In L. R. M. Alkhater, M. E. Tok, \& L. A. Pal (Eds.), Policy-making in a transformative state: The case of Qatar (pp. 131-153). Palgrave Macmillan.

Barth, M., \& Rieckmann, M. (2016). State of the art in research on higher education for sustainable development. In B. Matthias, G. Michelsen, M. R. Ian Thomas (Eds.), Routledge handbook of higher education for sustainable development (s. 100-13). Routledge.

Biasutti, M., Makrakis, V., Concina, E., \& Frate, S. (2018). Educating academic staff to reorient curricula in ESD. International Journal of Sustainable Higher Education, 19(1), 179-196.

Biggs, J. (2003). Aligning teaching for constructing learning. Open University Press.

Biggs, J. B., \& Tang, C. S. (2011). Teaching for quality learning at university: What the student does. (4th ed.). McGraw-Hill, Society for Research into Higher Education \& Open University Press.

Brabrand, C. (2008). Constructive alignment for teaching model-based design for concurrency. In M. W. P. van der Aalst Jensen, \& J. Billington (Eds.), Transactions on petri nets and other models of concurrency (pp. 1-18). Springer.

Brewer, D. J. (2007). Education for a new era: Design and implementation of K-12 education reform in Qatar. RAND-Qatar Policy Institute.

Cörvers, R., Wiek, A., de Kraker, J., \& Lang, D. J. (2016). Problem-based and project-based learning for sustainable development. In H. Heinrichs, P. Martens, G. Michelsen, \& A. Wiek (Eds.), Sustainability Science (pp. 349-58). Springer.

Darling-Hammond, L., \& Adamson, F. (2015). Beyond the bubble test: How performance assessments support 21st-century learning. Jossey Bass.

Dengler, M. (2008). Classroom active learning complemented by an online discussion forum to teach sustainability. Journal of Geography in Higher Education, 32(3), 481-494.

Dixson, D. D., \& Worrell, F. C. (2016). Formative and summative assessment in the classroom. Theory into Practice, 55(2), 153-159.

Dlouhá, J., Heras, R., Mulà, I., Salgado, F. P., \& Henderson, L. (2019). Competences to address SDGs in higher education: A reflection on the equilibrium between systemic and personal approaches to achieve transformative action. Sustainability, 11(13), 3664.

Du, X., Chaaban, Y., Mabrd, A. L., \& Y. M. (2019). Exploring the concepts of fidelity and adaptation in the implementation of project based learning in the elementary classroom: Case studies from Qatar. International Journal of Learning, Teaching and Educational Research, 18(9), 1-22.

Fadlelmula, F., \& Koc, M. (2016). Overall review of education system in Qatar. Lambert Academic Publishing.

Finnegan, L. A., Miller, K. M., Randolph, K. M., \& Bielskus-Barone, K. D. (2019). Supporting student knowledge using formative assessment and universal design for learning expression. Journal of Special Education Apprenceship, 8(2), 1-14. 
Fischer, D., \& Barth, M. (2014). Key competencies for and beyond sustainable consumption an educational contribution to the debate. GAIA-Ecological Perspectives on Science and Society, 23, 193-200.

Fisher, M. R. (2019). Student assessment in teaching and learning. Center for Teaching, Vanderbilt University. https://cft.vanderbilt.edu/student-assessment-in-teaching-and-learning

Gonzalez, G., Le, V. N., Broer, M., Mariano, L. T., Froemel, J. E., Goldman, C. A., \& DaVanzo, J. (2009). Lessons from the field: Developing and implementing the Qatar student assessment system, 2002-2006. RAND-Qatar Policy Institute.

GSDP [General Secretariat for Development Planning]. (2011). Qatar National Development Strategy 2011-2016: Towards Qatar National Vision 2030. Planning \& Statistics Authority. https://www. psa.gov.qa/en/nds1/Documents/Downloads/NDS_EN_0.pdf

GSDP. (2018a). Qatar National Vision 2030. Planning \& Statistics Authority. https://www.psa.gov.qa/ en/qnv1/Documents/QNV2030_English_v2.pdf

GSDP. (2018b). Qatar Second National Development Strategy 2018-2022: Towards Qatar National Vision 2030. Planning \& Statistics Authority.

Hill, K. (2017). Understanding classroom-based assessment practices: A precondition for teacher assessment literacy. Papers in Language Testing and Assessment, 6(1), 1-17.

Holgaard, J. E., Hadgraft, R., Kolmos, A., \& Guerra, A. (2016). Strategies for education for sustainable development: Danish and Australian perspectives. Journal of Cleaner Production, 112, 3479-3491.

Kolmos A. (1999). Progression of collaborative skills. In J. Conway \& A. Williams (Eds.), Themes and variations in problem-based learning. Vol. 1: Refereed Proceedings of the 1999 Biennial PBL Conference, July 7-10. Montreal, Canada.

MoEHE [Ministry of Education and Higher Education]. (2017). Annual statistics of education in the State of Qatar 2016-2017. MoEHE. https://www.edu.gov.qa/Documents/AnnualStatistics/EdAnnualStat/ AnnualStatistics2016-2017.pdf?csf=1e=C3fsgP

MoEHE. (2018a). Education in the schools of Qatar: Annual report for the academic year 2016-2017. MoEHE. https://www.edu.gov.qa/Documents/EvidenceStatisticsHigherEducation/Education_Chapt er_4_2017_AEshort.pdf\#search=Statistics

MoEHE. (2018b). Ministry of education and higher education strategy, 2017-2022. MoEHE. https://www. edu.gov.qa/en/Pages/AboutMinistry/AboutMinistry.aspx?ItemID=73 뺭

M. Z. (2019). Personal communication with a teacher in a preparatory girls' school in Doha, Qatar.

Nevin, E. (2008). Education and sustainable development. Policy \& Practice: A Development Education Review, 6, 49-62.

Nordensvaard, J. (2014). Dystopia and dysutopia: Hope and hopelessness in German pupils' future narratives. Journal of Educational Change, 15(4), 443-465.

Ortega-Sanchez, C. (2016). Written exams: How effectively are we using them? Procedia: Social and Behavioral Sciences, 228, 144-48.

Pappas, E., Pierrakos, O., \& Nagel, R. (2012). Using Bloom's Taxonomy to teach sustainability in multiple contexts. Journal of Cleaner Production, 48, 54-64.

Pierre, G., Sanchez Puerta, M. L., Valerio, A., \& Rajadel, T. (2014). STEP skills measurement surveys: Innovative tools for assessing skills. World Bank Group. https://openknowledge.worldbank.org/handle/ $10986 / 19985$

Price, M., O’Donovan, B., \& Rust, C. (2001). Strategies to develop students' understanding of assessment criteria and processes. In C. Rust (Ed.), Improving student learning strategically. 8th Symposium on Improving Student Learning. Oxford Centre for Staff and Learning Development.

Quyen, D. T. N., \& Khairani, Z. M. (2017). Reviewing the challenges of implementing formative assessment in Asia: The need for a professional development program. Journal of Social Science Studies, $4(1), 160-177$.

Ramirez, F. O., Schofer, E., \& Meyer, J. W. (2018). International tests, national assessments, and educational development (1970-2012). Comparative Education Review, 62(3), 344-364.

Rust, C. (2002). The impact of assessment on student learning: How can the research literature practically help to inform the development of departmental assessment strategies and learner-centred assessment practices? Active Learning in Higher Education, 3(2), 145-158.

Said, Z. (2016). Science education reform in Qatar: Progress and challenges. Eurasia Journal of Mathematics, Science \& Technology Education, 12(8), 2253-2265.

UNESCO. (2012). Education for sustainable development. Learning \& Training Tools, 4. https://unesdoc. unesco.org/ark:/48223/pf0000216383.locale=en

UNESCO. (2017). Education for sustainable development goals: Learning objectives. https://www.unesco. ch/wp-content/uploads/2017/01/Learning-objectives.pdf 
Wilhelm, S., Förster, R., \& Zimmermann, A. (2019). Implementing competence orientation: Towards constructively aligned education for sustainable development in university-level teaching and learning. Sustainability, 11(7), 1891.

Yunianta, A., Othman, M. S., Yusof, N., Mi Yusuf, L., Juwairiah, J., \& Selamat, N. S. (2015). Analysis and identification the complexity of data heterogeneity on learning environment using ontology. TELKOMNIKA: Telecommunication Computing Electronics and Control, 13, 1-13.

Zhou, K. (2016). Non-cognitive skills: Definitions, measurement and malleability. Background paper prepared for the Global Education Monitoring Report: "Education for people and planet: Creating sustainable futures for all”. UNESCO. https://unesdoc.unesco.org/ark:/48223/pf0000245576

Publisher's Note Springer Nature remains neutral with regard to jurisdictional claims in published maps and institutional affiliations.

Mona M. Al-Kuwari holds a PhD in Sustainability Studies from Hamad Bin Khalifa University (HBKU). She also has an MA in Computing from the College of Engineering and a BA in Statistics from the College of Science, both from Qatar University. Her main research interests focus on performance assessment strategies and frameworks in the context of the ESD and the SDGs. In 2014, she joined the Qatar Foundation as a program analyst in Qatar National Research Fund (QNRF). Before joining QNRF, she spent over eight years as a statistician, holding the position of the Head of Statistical Department, Ministry of Education and Higher Education.

Xiangyun Du is a professor in the College of Education, Qatar University, and at Aalborg University's UNESCO Center for Problem and Project Based Learning in Denmark. Her main research interests focus on pedagogical development, particularly problem-based and project-based learning methods in fields ranging from engineering, medicine and health, foreign languages, and teacher education, within diverse social, cultural, and educational contexts. She has also engaged with educational institutions in over 20 countries in substantial work on pedagogy and curricula development. Dr. Du has over 160 relevant international publications, including monographs, international journal papers, and edited books and book chapters, as well as conference contributions.

Muammer Koç is a founding professor of Sustainability Studies at HBKU from 2014. Before that he held professor, director, chair and dean positions at different universities in Turkey and the USA between 2000 and 2014. He has a PhD in Industrial and Systems Engineering from the Ohio State University (1999) and an Executive MBA degree from the University of Sheffield, UK (2014). He has published 130+ publications in various international journals and conferences, edited three books, and organized, chaired, and co-chaired various international conferences, workshops and seminars on design, manufacturing and product development. In addition to his academic and educational activities, he provides consulting services to industry, government and educational institutes for strategic transformation, business optimization, organizational efficiency, lean operations, restructuring and reengineering initiatives. 